\title{
Regulatory Network of MicroRNAs, Host Genes, Target Genes and Transcription Factors in Human Esophageal Squamous Cell Carcinoma
}

\author{
Tian-Yan Wang ${ }^{1,3}$, Zhi-Wen $\mathrm{Xu}^{2,3 *}$, Kun-Hao Wang ${ }^{2,3}$, Ning Wang ${ }^{2,3}$
}

\begin{abstract}
Abnormally expressed microRNAs (miRNAs) and genes have been found to play key roles in esophageal squamous cell carcinoma (ESCC), but little is known about the underlying mechanisms. The aim of this paper was to assess inter-relationships and the regulatory mechanisms of ESCC through a network-based approach. We built three regulatory networks: an abnormally expressed network, a related network and a global network. Unlike previous examples, containing information only on genes or miRNAs, the prime focus was on relationships. It is worth noting that abnormally expressed network emerged as a fault map of ESCC. Theoretically, ESCC might be treated and prevented by correcting the included errors. In addition, the predicted transcription factors (TFs) obtained by the P-match method also warrant further study. Our results may further guide gene therapy researchers in the study of ESCC.
\end{abstract}

Keywords: Esophageal squamous cell carcinoma - genes - microRNAs - network - transcription factors

Asian Pac J Cancer Prev, 16 (9), 3677-3683

\section{Introduction}

Esophageal squamous cell carcinoma (ESCC) is a malignant neoplasm, which is a main histological type of esophageal cancer (EC). It is highly aggressive and always associated with a poor prognosis (Jing et al., 2014). Thus, there is a great need to disclose pathogenesis of ESCC.

MicroRNAs (MiRNAs) are an endogenous class of non-coding RNA molecules, which regulate gene expression at the post-transcriptional level either via the degradation of target mRNAs or the inhibition of protein translation (Zhang et al., 2014). MiRNAs have a role in the biological process, such as proliferation, cell differentiation and apoptosis (Sakai et al., 2013). They are emerging as important regulators in cancer cells, because such a tiny molecule can regulate dozens of genes at the same time, which makes it as a powerful molecule. Numerous miRNAs have turned out to involve in tumorigenesis.

Transcription factors (TFs) are main and important factors that can regulate gene expression at the transcriptional level by the way of promotion or suppression (Tran et al., 2010). TFs function by binding to the upstream regions of genes individually or joint with other proteins. A substantial number of TFs have been shown to play a pivotal role in the initiation and progression of ESCC.
A wide range of genes, which is targeted by miRNAs, is usually known as target genes (targets). These targets are helpful to reveal the biological role of miRNAs. There are many databases have supplied sufficient resources to investigate the relationship between miRNAs and their targets.

Some miRNAs locate on the genes and the genes are bound to them as their host genes. Numerous miRNAs and the corresponding host genes were observed to correlate strongly (Baskerville et al., 2005). And miRNAs and their host genes are transcribed simultaneously (Rodriguez et al., 2004).

A considerable quantity of experiments in the field of ESCC has been conducted by scientists, and abnormally expressed genes and miRNAs were deemed to result in development of ESCC. However, most of these experiments are unilateral. They analyzed from a certain angle, gene or miRNA, which makes the pathogenesis of ESCC remain unclear. This study is aimed at investigating regulatory mechanism of ESCC through centering on all the elements (miRNAs, host genes, targets and TFs). Three kinds of experimentally validated associations, including miRNAs and the respective host genes, TFs and miRNAs, as well as miRNAs and the corresponding target genes, were gathered from databases and pertinent literatures to construct three regulatory networks (an abnormally expressed network, a related network and a

${ }^{I}$ College of Software Engineering, ${ }^{2}$ College of Computer Science and Technology, ${ }^{3}$ Key Laboratory of Symbolic Computation and Knowledge Engineering of the Ministry of Education, Jilin University, Changchun, Jilin, China*For correspondence: xuzw@jlu . edu.cn 
Tian-Yan Wang et al

global network). This study may provide novel insights for the study of ESCC.

\section{Materials and Methods}

Dataset of experimentally validated regulating relations between TFs and corresponding miRNAs

For the first step, we extracted the dataset of human TFs and miRNAs from the TransmiR database (Wang et al., 2010) that can be accessed online at http://www.cuilab. $\mathrm{cn} /$ transmir. Data of TransmiR were extracted from public literatures and biological experiments.

Dataset of experimentally validated targeting relations between miRNAs and target genes

The dataset of miRNAs and the corresponding targets was collected from two databases, Tarbase 5.0 (Papadopoulos et al., 2009) and miRTarBase (Hsu et al., 2011), for the second step.

\section{Dataset of miRNAs and host genes}

The third step is to extract the host genes of the human miRNAs from National Centre for Biotechnology Information (NCBI) database (http://www.ncbi.nlm.nih. gov/gene/) and miRBase (Kozomara et al., 2011).

\section{Abnormally expressed and related genes associated with ESCC}

The fourth step, we retrieved the dataset of abnormally expressed genes from Cancer Genetics Web (http:// www.cancerindex.org/geneweb/index.html) and related SCI studies. The dataset of related genes were collected from GeneCards database (Safran et al., 2010) (http:// www.cancerindex.org/geneweb/index.html) and relevant literatures. Here, abnormally expressed genes are a part of related genes, as well as the predicted TFs extracted by $\mathrm{P}$-match method. P-match method is a tool for recognition of TF binding sites (TFBSs) in gene regulatory regions of genomes (Chekmenev et al., 2005). We used the 1,000nt promoter region sequences of the targets, which were downloaded from University of California Santa Cruz (UCSC) database (Fujita et al., 2011), as an input to get the predicted TFs. Note that the targets are targeted by abnormally expressed miRNAs. And the TFs, which appeared in TransmiR, were termed the related genes.

Abnormally expressed and related miRNAs in ESCC

The last step, we picked up the abnormally expressed miRNAs from Kyoto Encyclopedia of Genes and Genomes (KEGG) pathway database (Kanehisa et al., 2000), mir2Disease (Jiang et al., 2009) and recently related SCI studies. Similarly, the related miRNAs were retrieved from the Human microRNA Disease Database (HMDD) (Li et al., 2014) which can be accessed at http://cmbi.bjmu. edu.cn/hmdd, the abnormally expressed miRNAs and information from previous relevant literatures on ESCC.

These experimentally validated data were collected in a scattered form. The official symbol from NCBI database was used to unify all miRNAs and genes in this paper.

\section{Networks construction}

We constructed three regulatory networks of ESCC: abnormally expressed, related and global network. We extracted the abnormally expressed genes and miRNAs as well as the associations of them to get the abnormally expressed network. As a core network, abnormally expressed network shows key hubs and linkages in progression of ESCC. Besides, the related network was derived as a result of combining the related elements that are involved in the pathogenesis of ESCC and the

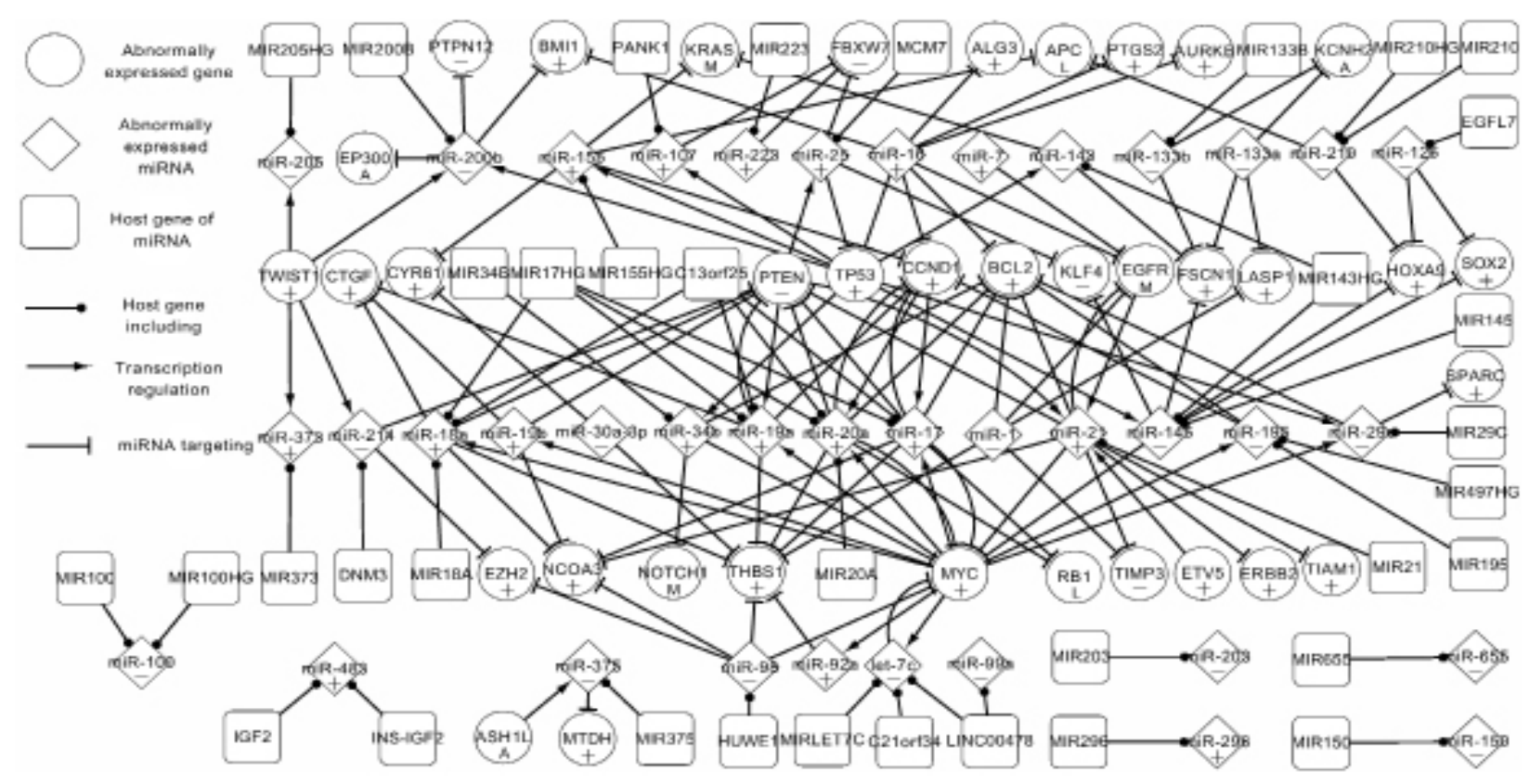

Figure 1. Abnormally Expressed Network Consisting Of Abnormally Expressed Genes, miRNAs and their Host Genes in ESCC. Expression pattern that includes the symbols of +,-, A, L, M shows the expression level of abnormally expressed factors compared with the normal tissue. The symbol of + represents up-regulated, highly expressed, overexpressed, elevated, amplification and increased. The symbol of - represents down-regulated, decreased and lower level. The symbol of A represents altered and aberrantly expressed. The symbol of $\mathrm{L}$ represents homozygous deletion. The symbol of $\mathrm{M}$ represents mutated 
relations of them. Obviously the related network contains the abnormally expressed network. The global network is an experimentally validated regulatory network, which incorporates the abnormally expressed and related networks. It was constructed by combining all associations among miRNAs, TFs, targets and host genes.

\section{Results}

\section{Abnormally expressed network of ESCC}

Figure 1 demonstrates a number of essential regulatory relations of significant elements, which may result in the occurrence of ESCC. We investigated the interactions between miRNAs and targets, TFs and miRNAs and miRNAs and the respective host genes. Figure 1 is made up of eight TFs, thirty-three targets, thirty-eight miRNAs and thirty-six host genes. Five TFs (EGFR, PTEN, MYC, TP53 and CCND1) are also as part of targets. Apart from the host genes, all nodes are abnormally expressed.

In Figure 1, some data linkages present special characteristics. For instance, ETV5 regulates miR-21 that targets PTEN. And PTEN acts as the TF of miR25, which in turn targets FBXW7. It is indicated that precursors orderly influence their successors. Furthermore, some self-adaptation associations are prominent in this network. For example, miR-17 targets CCND1 meanwhile miR-17 is regulated by CCND1. Therefore, miR-17 and CCND1 constitute a feedback loop. Moreover, genes like ERBB2 only targeted by some miRNAs but do not regulate any miRNAs and miRNAs like miR-205 only regulated by some TFs but do not target any genes, may be the last actors in this network. Likewise, certain nodes without predecessors, including the miRNAs of miR223, miR-16, miR-7, miR-133a, miR-133b, miR-210, miR-126, miR-30a-3p, miR-1 and miR-98, and the TFs of TWIST1, ASH1L and ETV5, may be the first actors in abnormally expressed network. These first actors are regarded as switches of abnormally expressed network, which are considered as the beginning of causing cancers. These nodes may exert key biological functions in some processes. For example, CTGF has essential roles in many biological processes, such as angiogenesis, skeletal development, and tissue wound repair, and is critically involved in fibrotic disease and several forms of cancers
(Hall-Glenn et al., 2011; Jun et al., 2011; Kubota et al., 2011). It is important for us to find the switches of abnormally expressed network. If critical hubs can be adjusted to a normal state via these switches, ESCC may be controlled in theory.

Host genes may be involved in certain ESCC processes despite the fact that they are not abnormally expressed genes. Here, we considered them as abnormally expressed genes as long as their miRNAs are abnormally expressed. Host genes and corresponding miRNAs exhibit some specific features in this network. Figure 1 depicts that an individual host gene may include multiple miRNAs that together target some genes. C13orf25 and MIR17HG contain miR-17, miR-18a, miR-19a and miR-20a that together target THBS1. MIR143HG encodes miR-143 and miR-145, which target FSCN1. Additionally, an individual miRNA may be located in several genes. let-7c is found to be present in C21 orf34, LINC00478 and MIRLET7C. Regulation of abnormally expressed network may be a scheme on gene therapy in ESCC.

\section{Related network of ESCC}

ESCC-related network can be regarded as an extension of abnormally expressed network based on the fact that the abnormally expressed genes and miRNAs are seen as related ones. ESCC-related network contains mass additional elements and regulatory relations, which have potential relationship with cancer. Given the related network is too complex, we extracted a subnet of it to describe the related network clearly. Figure 2 focuses on the interaction relationship between the abnormally expressed and related factors. As can be seen, PTEN, which is an abnormally expressed TF, regulates four miRNAs (miR-19a, miR-25, miR-22 and miR-302b). Two of these miRNAs (miR-19a and miR-25) are abnormally expressed and others are not. As a related gene, AKT1 regulates miR-22 and miR-155. miR-22 is related expressed while miR-155 is abnormally expressed. miR-22 targets PTEN, BMP7 and TFRC. We also noticed that BMP7 and TFRC are related genes. miR-155, as an abnormally expressed miRNA, targets four abnormally expressed genes (APC, CCND1, KRAS and CYR61) and eleven related genes (CTNNB1, CUX1, FADD, LY6K, MET, MLH1, MSH2, PPL, PRKCI, RHOA and SOCS1).

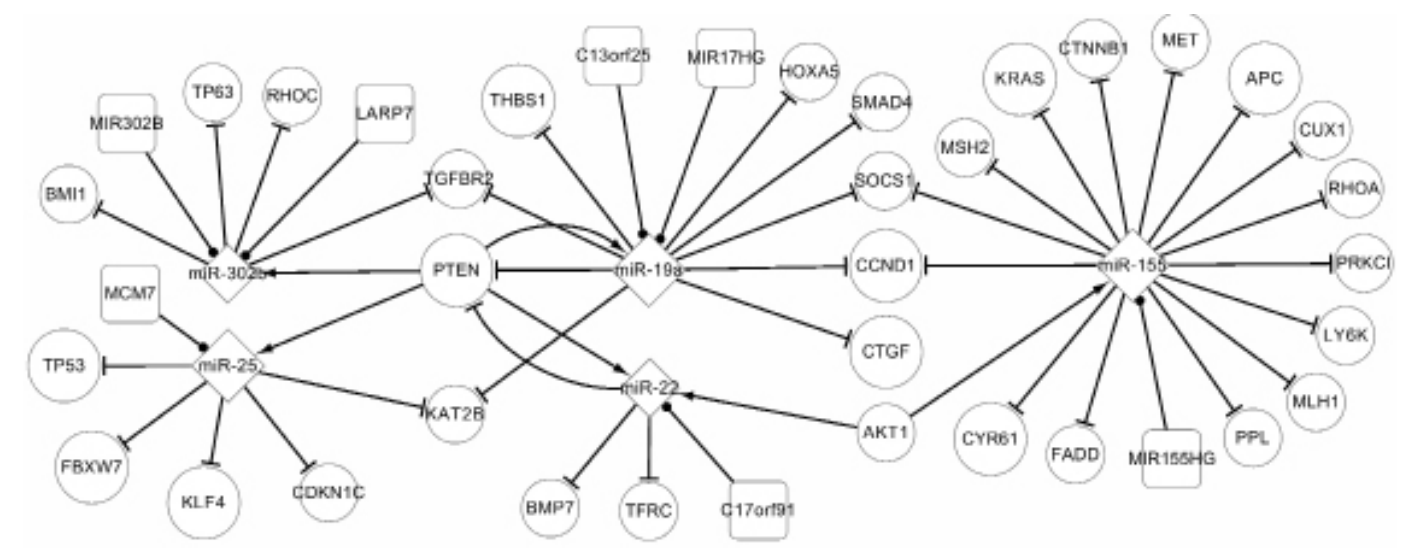

Figure 2. A subnet of Related Network about Genes and miRNAs in ESCC. MiRNAs are presented as diamonds, abnormally expressed and related genes are eclipses, and host genes are presented as rounded rectangles. The nodes of related factors that not abnormally expressed are smaller than abnormally expressed ones 


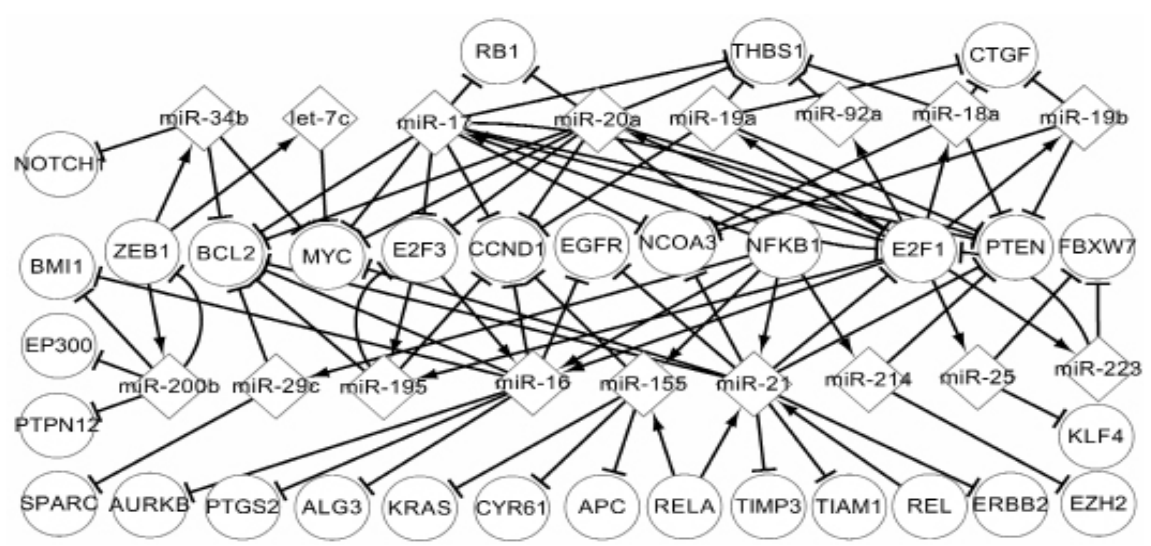

Figure 3. The Transcriptional Network of Predicted TFs, abnormally Expressed miRNAs and Target Genes in ESCC

Figure 2 shows that the abnormally expressed and related data interact with each other to affect the progression of ESCC. The related network has close relation with the mechanism of ESCC. It is helpful to further understand the progression of ESCC.

\section{Global network of ESCC}

The abnormally expressed and related networks are included in global network. It has more additional elements and comprehensive regulatory correlations, which have been experimentally validated. Since the global network is so complex that the pathways associated with ESCC could not be easily identified. In the present study, we mainly center on the other two networks (abnormally expressed and related network), and the global network is considered to be an auxiliary tool.

\section{Transcriptional network of predicted TFs}

The predicted TFs are able to affect the progression of ESCC. In Figure 3, we further analyzed the regulatory associations among these predicted TFs, abnormally expressed miRNAs and targets in ESCC. Figure 3 shows that an individual target may be targeted by multiple abnormally expressed miRNAs and an individual abnormally expressed miRNA may be regulated by multiple TFs. For instance, NCOA3 is targeted by miR-21, miR-17, miR-18a and miR-19b; miR-16 is regulated by NFKB1, E2F1 and E2F3. It is also possible to conclude that a TF indirectly influences other TFs by some abnormally expressed miRNAs and an abnormally expressed miRNA indirectly influences other miRNAs by certain genes. For example, E2F1 regulates E2F3 by miR-20a; and miR-200b affects miR-34b via ZEB1. This transcription network is helpful in further understanding nosogenesis of ESCC.

Regulatory relations about abnormally expressed genes

We picked up the upstream and downstream information of major elements including predicted TFs, abnormally expressed genes and miRNAs for analyzing the interacting features of them. For the abnormally expressed genes, PTEN is used as an example. Table 1

Table 1. Regulatory relations between miRNAs and PTEN

\begin{tabular}{|c|c|c|c|c|c|c|}
\hline \multicolumn{3}{|c|}{ Upstream } & \multirow[b]{2}{*}{ Gene symbol } & \multicolumn{3}{|c|}{ Downstream } \\
\hline $\begin{array}{l}\text { Abnormally } \\
\text { expressed network }\end{array}$ & $\begin{array}{l}\text { Related } \\
\text { network }\end{array}$ & $\begin{array}{l}\text { Global } \\
\text { network }\end{array}$ & & $\begin{array}{c}\text { Abnormally } \\
\text { expressed network }\end{array}$ & $\begin{array}{l}\text { Related } \\
\text { network }\end{array}$ & $\begin{array}{l}\text { Global } \\
\text { network }\end{array}$ \\
\hline $\begin{array}{l}\text { miR-19a } \\
\text { miR-21 } \\
\text { miR-18a } \\
\text { miR-17 } \\
\text { miR-19b } \\
\text { miR-20a } \\
\text { miR-214 }\end{array}$ & $\begin{array}{l}\text { miR-19a } \\
\text { miR-21 } \\
\text { miR-18a } \\
\text { miR-17 } \\
\text { miR-19b } \\
\text { miR-20a } \\
\text { miR-214 } \\
\text { miR-141 } \\
\text { miR-22 }\end{array}$ & $\begin{array}{l}\text { miR-19a } \\
\text { miR-21 } \\
\text { miR-18a } \\
\text { miR-17 } \\
\text { miR-19b } \\
\text { miR-20a } \\
\text { miR-214 } \\
\text { miR-141 } \\
\text { miR-22 } \\
\text { miR-106b } \\
\text { miR-216a } \\
\text { miR-217 } \\
\text { miR-221 } \\
\text { miR-222 } \\
\text { miR-26a } \\
\text { miR-29a } \\
\text { miR-29b-3p } \\
\text { miR-519a-3p } \\
\text { miR-494 } \\
\text { miR-519d } \\
\text { miR-93-5p }\end{array}$ & PTEN & $\begin{array}{l}\text { miR-19a } \\
\text { miR-21 } \\
\text { miR-25 }\end{array}$ & $\begin{array}{l}\text { miR-19a } \\
\text { miR-21 } \\
\text { miR-25 } \\
\text { miR-22 } \\
\text { miR-302b }\end{array}$ & $\begin{array}{l}\text { miR-19a } \\
\text { miR-21 } \\
\text { miR-25 } \\
\text { miR-22 } \\
\text { miR-302b } \\
\text { miR-302a } \\
\text { miR-302c } \\
\text { miR-302d } \\
\text { miR-302e } \\
\text { miR-302f }\end{array}$ \\
\hline
\end{tabular}


Regulatory Network of MicroRNAs, Host Genes, Target Genes and Transcription Factors in Human Esophageal SCC

Table 2. Regulatory Relations between miR-195 and Genes

\begin{tabular}{lcccccc}
\hline & \multicolumn{2}{c}{ Upstream } & & & \multicolumn{3}{c}{ Downstream } \\
\cline { 5 - 6 } $\begin{array}{l}\text { Abnormally expressed } \\
\text { network }\end{array}$ & $\begin{array}{c}\text { Related } \\
\text { network }\end{array}$ & $\begin{array}{c}\text { Global } \\
\text { network }\end{array}$ & MiRNA symbol & $\begin{array}{c}\text { Abnormally expressed } \\
\text { network }\end{array}$ & $\begin{array}{c}\text { Related } \\
\text { network }\end{array}$ & $\begin{array}{c}\text { Global } \\
\text { network }\end{array}$ \\
\hline MYC & MYC & MYC & miR-195 & BCL2 & BCL2 & BCL2 \\
& E2F3 & E2F3 & & CCND1 & CCND1 & CCND1 \\
& E2F1 & E2F1 & & CDK6 & CDK6 \\
& & EGR3 & STAT5B & & KRT7 & KRT7 \\
& & & & E2F3 & E2F3 \\
& & & & MECP2 \\
& & & & & SKI \\
& & & & & VEGFA \\
& & & & & WEE1 \\
\hline
\end{tabular}

Table 3. Regulatory Relations between E2F3 and miRNAs

\begin{tabular}{|c|c|c|c|c|c|c|}
\hline \multicolumn{3}{|c|}{ Upstream } & \multirow[b]{2}{*}{ Gene symbol } & \multicolumn{3}{|c|}{ Downstream } \\
\hline $\begin{array}{l}\text { Abnormally expressed } \\
\text { network }\end{array}$ & $\begin{array}{l}\text { Related } \\
\text { network }\end{array}$ & $\begin{array}{l}\text { Global } \\
\text { network }\end{array}$ & & $\begin{array}{c}\text { Abnormally expressed } \\
\text { network }\end{array}$ & $\begin{array}{l}\text { Related } \\
\text { network }\end{array}$ & $\begin{array}{c}\text { Global } \\
\text { network }\end{array}$ \\
\hline $\begin{array}{l}\text { miR-17 } \\
\text { miR-195 } \\
\text { miR-20a } \\
\text { miR-210 }\end{array}$ & $\begin{array}{l}\text { miR-17 } \\
\text { miR-195 } \\
\text { miR-20a } \\
\text { miR-210 } \\
\text { miR-34a }\end{array}$ & $\begin{array}{l}\text { miR-17 } \\
\text { miR-195 } \\
\text { miR-20a } \\
\text { miR-210 } \\
\text { miR-34a } \\
\text { miR-106 } \\
\text { miR-125 } \\
\text { miR-128 } \\
\text { miR-200 } \\
\text { miR-203 } \\
\text { miR-34c }\end{array}$ & E2F3 & $\begin{array}{l}\operatorname{miR}-16 \\
\operatorname{miR}-195\end{array}$ & $\begin{array}{l}\text { miR-16 } \\
\text { miR-195 } \\
\text { miR-34a }\end{array}$ & $\begin{array}{l}\text { miR-16 } \\
\text { miR-195 } \\
\text { miR-34a } \\
\text { miR-34b } \\
\text { miR-34c } \\
\text { miR-106b } \\
\text { let-7a-1 } \\
\text { let-7a-2 } \\
\text { let-7a-3 } \\
\text { let-7i } \\
\text { miR-15a } \\
\text { miR-15b }\end{array}$ \\
\hline
\end{tabular}

shows PTEN, upstream and downstream of PTEN and their regulatory relations in three networks (abnormally expressed network, related network and global network). The upstream indicates some miRNAs that target PTEN and the downstream refers to some miRNAs that are regulated by PTEN. There are seven miRNAs target PTEN and PTEN regulates three miRNAs in the abnormally expressed network. Nine miRNAs target PTEN that regulates five miRNAs in the related network. Twenty-one miRNAs target PTEN which regulates ten miRNAs in the global network. Table 1 demonstrates that the downstream of PTEN is indirectly regulated by the upstream via PTEN. Moreover, some TFs indirectly influence PTEN by some miRNAs. For example, CCND1 regulates miR-17 that targets PTEN. PTEN also affect the expression of certain genes through some miRNAs. PTEN regulates miR-21 that targets MYC. Besides, we can see that miR-19a and miR-21 target PTEN and PTEN regulates them in return, which form self-adaption associations in three networks. These data linkages must be crucial in progression of ESCC.

Regulatory relations about abnormally expressed miRNAs

We used the same method to analyze the abnormally expressed miRNAs pathways. Table 2 lists the upstream and downstream of miR-195 in abnormally expressed network, related network and global network. The upstream shows off some genes that regulate miR-195 and the downstream shows some targets of miR-195 in three networks. There is one gene regulates miR-195 that targets two genes in the abnormally expressed network. There are three genes regulate miR-195 that targets five genes in the related network. There are five genes regulate miR-195 that targets nine genes in the global network. The upstream of miR-195 indirectly affects the downstream through miR-195. E2F3 and miR-195 were observed to form a feedback loop. Furthermore, certain miRNAs indirectly influence miR-195 by targeting some genes and miR-195 affects other miRNAs by some genes. For instance, miR-145 targets MYC, yet it regulates miR-195; miR-195 affects the expression of miR-20a by CCND1.

Regulatory relations about predicted Transcription factors

Then using the aforementioned method to compare and analyze the predicted TFs. In the following part, only E2F3 be focused on. Table 3 shows E2F3, and its upstream and downstream in three networks. The upstream shows some miRNAs that target E2F3 in three networks and the downstream shows some miRNAs that are regulated by E2F3 in three networks. In abnormally expressed network, there are four miRNAs target E2F3 which regulates two miRNAs. Five miRNAs target E2F3 that regulates three miRNAs in related network. In global network, eleven miRNAs target E2F3 and E2F3 even regulates twelve miRNAs. E2F3 and miR-195 were identified to form a self-adaption relation in three networks. miR-34a and E2F3 were found to form self-adaption relations in related network and global network. miR-106b and miR$34 \mathrm{c}$ separately form feedback loops with E2F3 in global network.

Asian Pacific Journal of Cancer Prevention, Vol 16, 2015 


\section{Discussion}

In this study, we derived three level networks from a great many of comprehensive data and experimentally validated relations associated with ESCC. Abnormally expressed network is used as a core misregulation network. It is composed of numerous abnormal data and linkages, which result in the occurrence of ESCC. Theoretically, ESCC can be treated and prevented by correcting the errors to reach a normal state.

In abnormally expressed network, there are some critical data linkages showing notable features, for example TWIST1-miR-214-PTEN-miR-25-TP53-miR-34b-MYCmiR-92a-THBS1. Each hub has its critical function. TWIST1 is associated with epithelial-mesenchymal transition of ESCC (Lee et al., 2012). Zhou et al. (2013) elucidated that miR-214 play a key role in the pathogenesis of ESCC. PTEN, as a tumor suppressor gene, is involved in the regulation of the cell cycle, preventing cells from growing and dividing too rapidly (Chu et al., 2004). Xu et al. (2012) demonstrated that miR-25 promotes cell migration and invasion in ESCC. TP53, as a significant tumor suppressor, is closely associated with apoptosis and the differentiation of cancer cells (Huang et al., 2014). miR-34b has an oncogenic role in ESCC (Harata et al., 2010). MYC is a proto-oncogene and it functions as a transcription factor. Chen et al. (2011) indicated that miR-92a promotes ESCC cell migration and invasion. THBS1 has been demonstrated to be a natural inhibitor of neovascularization and tumorigenesis in healthy tissue. These mutated data linkages perform key biological functions in ESCC. Moreover, some data linkages have been observed in other carcinomas. For instance, RB1 is targeted by miR-17 and miR-20a in Retinoblastoma ( $\mathrm{Li}$ et al., 2013). We notice that the feedback loop of miR-21 and EGFR is also found in adrenocortical cancer (Zhang et al., 2013). And the pathway that BCL2 is targeted by miR-17 is also present in neuroblastoma (Wang et al., 2014). It indicates that the relations among genes from one kind carcinoma to another can be expanded.

Related network is an extension of abnormally expressed network. The related factors affect the pathogenesis of ESCC by interacting with abnormally expressed factors. Thus, it has potential relationship with nosogenesis of ESCC. Global network is an experimentally validated network in human body, which is helpful for the research of ESCC.

The discovery of these networks provides a basis for further experimental studies of ESCC. Additionally, the predicted TFs extracted by P-match method, which need further verify by experiments, should be paid more attention to. Our study partly reveals the pathogenesis of ESCC and provides a new vision for the future research of ESCC.

\section{Acknowledgements}

This study was supported by the Science and Technology Development Plan of Jilin Province (NO. 20130101166JC).

\section{References}

Baskerville S, Bartel DP (2005). Microarray profiling of microRNAs reveals frequent coexpression with neighboring miRNAs and host genes. RNA, 11, 2417.

Chekmenev DS, Haid C, Kel AE (2005). P-Match: transcription factor binding site search by combining patterns and weight matrices. Nucleic Acids Res, 33, 432-7.

Chen ZL, Zhao XH, Wang JW, et al (2011). microRNA-92a promotes lymph node metastasis of human esophageal squamous cell carcinoma via E-cadherin. J Biol Chem, 286, 10725-34.

Chu EC, Tarnawski AS (2004). PTEN regulatory functions in tumor suppression and cell biology. Med Sci Monit, 10, 235-41.

Fujita PA, Rhead B,Zweig AS, et al (2011). The UCSC genome browser database: update 2011. Nucleic Acids Res, 39, 876-82.

Hall-Glenn F, Lyons KM (2011). Roles for CCN2 in normal physiological processes. Cell Mol Life Sci, 68, 3209-17.

Harata K, Ishiguro H, Kuwabara Y, et al (2010). MicroRNA$34 \mathrm{~b}$ has an oncogenic role in esophageal squamous cell carcinoma. Oncol Lett, 1, 685-9.

Hsu SD, Lin FM, Wu WY, et al (2011). miRTarBase: a database curates experimentally validated microRNA-target interactions. Nucleic Acids Res, 39, 163-9.

Huang K, Chen L, Zhang J, et al (2014). Elevated p53 expression levels correlate with tumor progression and poor prognosis in patients exhibiting esophageal squamous cell carcinoma. Oncol Lett, 8, 1441-6.

Jiang Q, Wang Y, Hao Y, et al (2009). miR2Disease: a manually curated database for microRNA deregulation in human disease. Nucleic Acids Res, 37, 98-104.

Jing JX, Wang Y, Xu XQ, et al (2014). Tumor markers for diagnosis, monitoring of recurrence and prognosis in patients with upper gastrointestinal tract cancer. Asian Pac J Cancer Prev, 15, 10267-72.

Jun JI, Lau LF (2011). Taking aim at the extracellular matrix: CCN proteins as emerging therapeutic targets. Nat Rev Drug Discov, 10, 945-63.

Kanehisa M, Goto S (2000). KEGG: kyoto encyclopedia of genes and genomes. Nucleic Acids Res, 28, 27-30.

Kozomara A, Griffiths-Jones S (2011). miRBase: integrating microRNA annotation and deep-sequencing data. Nucleic Acids Res, 39, 152-7.

Kubota S, Takigawa M (2011). The role of CCN2 in cartilage and bone development. J Cell Commun Signal, 5, 209-17.

Lee KW, Kim JH, Han S, et al (2012). Twist 1 is an independent prognostic factor of esophageal squamous cell carcinoma and associated with its epithelial-mesenchymal transition. Ann Surg Oncol, 19, 326-35.

Li J, Xu ZW, Wang KH, et al (2013). The network about microRNAs and genes in retinoblastoma. Asian Pac J Cancer Prev, 14, 6631-6.

Li Y, Qiu C, Tu J, et al (2014). HMDD v2.0: a database for experimentally supported human microRNA and disease associations. Nucleic Acids Res, 42, 1070-4.

Papadopoulos GL, Reczko M, SimECsis VA, Sethupathy P, Hatzigeorgiou AG (2009). The database of experimentally supported targets: a functional update of TarBase. Nucleic Acids Res, 37, 155-8.

Rodriguez A, Griffiths-Jones S, Ashurst JL, Bradley A (2004). Identification of mammalian microRNA host genes and transcription units. Genome Res, 14, 1902-10.

Safran M, Dalah I, Alexander J, et al (2010). GeneCards version 3: the human gene integrator. Database, 2010, baq020.

Sakai NS, Samia-Aly E, Barbera M, Fitzgerald RC (2013). 
Regulatory Network of MicroRNAs, Host Genes, Target Genes and Transcription Factors in Human Esophageal SCC A review of the current understanding and clinical utility of miRNAs in esophageal cancer. Semin Cancer Biol, 23, 512-21.

Tran DH, Satou K, Ho TB, Pham TH (2010). Computational discovery of miR TF regulatory modules in human genome. Bioinformation, 4, 371-7.

Wang J, Lu M, Qiu C, Cui Q (2010). TransmiR: a transcription factor-microRNA regulation database. Nucleic Acids Res, 38, 119-22.

Wang L, Che XJ, Wang N, Li J (2014). Regulatory network analysis of microRNAs and genes in neuroblastoma. Asian Pac J Cancer Prev, 15, 7645-52.

Xu X, Chen Z, Zhao X, et al (2012). MicroRNA-25 promotes cell migration and invasion in esophageal squamous cell carcinoma. Biochem Biophys Res Commun, 421, 640-5.

Zhang B, Xu ZW, Wang KH, et al (2013). Complex regulatory network of microRNAs, transcription factors, gene alterations in adrenocortical cancer. Asian Pac J Cancer Prev, 14, 2265-8.

Zhang F, Yang Z, Cao M, et al (2014). MiR-203 suppresses tumor growth and invasion and down-regulates MiR-21 expression through repressing Ran in esophageal cancer. Cancer Lett, 342, 121-9.

Zhou Y, Hong L (2013). Prediction value of miR-483 and miR214 in prognosis and multidrug resistance of esophageal squamous cell carcinoma. Genet Test Mol Biomarkers, 17, 470-4. 